\title{
VIRAL INFECTIONS AND FEBRILE SEIZURES
}

Among abstracts of the 19th annual conference on febrile convulsions, Tokyo, Japan, Dec 14, 1996, and reviewed by Dr Yukio Fukuyama (Brain Dev July $1997 ; 19: 369-374)$, four referred to the association with viral infection.

Abe T, Teikyo University School of Medicine, Tokyo, studied the mechanism of convulsions associated with rotavirus (RV) infection. Three percent of children with RV diarrhea develop convulsions compared to $0.3 \%$ with non-RV diarrheal infections. The mechanism may involve electrolyte imbalance or the direct invasion of neurons by RV virus or enterotoxin.

Asano $Y$ et al, Fujita School of Medicine, Toyoahe, Aichi, report on human herpesvirus 6 (HHV-6B) as a cause of febrile seizures in $8-36 \%$ of children with exanthem subitum. The viral DNA is found in CSF samples within 4 days after onset of infection. Afebrile seizures may also occur with HHV-6 infection and exanthem subitum and without evidence of invasion of the CNS by the virus. A vasculitis is proposed as the mechanism of afebrile seizures with HHV-6 infection. (Ojima K et al).

Kajitani T et al, Kawasaki Hospital, Okayama, reviewed the causes of fever in 197 children admitted with febrile seizures. Viral infections accounted for $82 \%$, of which $3 \%$ were exanthem subitum.

COMMENT. Seizures with fever, HHV-6 and exanthem subitum are frequently prolonged, recurrent, and complex, and sometimes a manifestation of encephalitis or encephalopathy. HHV-6 infection and febrile seizures are reviewed in Progress in Pediatric Neurology III, 1997, pp 24-28; VOL II, pp $27-$ 28.

\section{ATTENTION DEFICIT AND LEARNING DISORDERS}

\section{LONG-TERM STIMULANT THERAPY AND ADHD OUTCOME}

The long-term effects of amphetamine sulfate $(5 \mathrm{mg} \mathrm{AM}$ and lunchtime, increasing to a mean dose of $17 \mathrm{mg} / \mathrm{d}, 0.52 \mathrm{mg} / \mathrm{kg}$ body weight, and a maximum of $45 \mathrm{mg} / \mathrm{d}$ ) were evaluated in 62 children, aged 6 to 11 years, with ADHD treated for 15 months in a randomized, double-blind, placebo-controlled study at the Child and Adolescent Psychiatry University departments in Goteborg, Uppsala, Malmo-Lund, and Umea, Sweden. Twent six (42\%) had comorbid diagnoses, including pervasive developmental disorders, mild retardation, and oppositional defiant disorder. Treatment was stopped or changed to open treatment, usually within 3 months, in $71 \%$ of the placebo group and $29 \%$ of those receiving amphetamine. Amphetamine was superior to placebo in effects on inattention, hyperactivity, and disruptive behaviors, measured by Conners parent and teacher scores, and on scores on the WISC-R. The mean change in IQ from 0 to $>9$ months was +4.5 with amphetamine and +0.7 for placebo for 6 months or more. Decreased appetite occurred in $56 \%$ of the amphetamine group. Abdominal pain recorded in $32 \%$ was no more frequent during amphetamine treatment than placebo. Tics diagnosed before baseline in 4 children were exacerbated during double-blind amphetamine $(15 \mathrm{mg} / \mathrm{d})$ in one; 18 developed tics during the study but placebo and amphetamine were equally represented. Visual hallucinations occurred in 3 during amphetamine and required reduction in dose or drug withdrawal. Amphetamine inhibited weight gain but had no significant effect on growth. (Gillberg C, Melander H, von Knorring A-L et al. Long-term stimulant treatment of children with 
attention-deficit hyperactivity disorder symptoms. Arch Gen Psychiatry September 1997;54:857-864). (Reprints: Christopher Gillberg MD, PhD, Department of Child and Adolescent Psychiatry, University of Goteborg, Annedals Clinics, S 41345 Goteborg, Sweden).

COMMENT. Long-term treatment of ADHD with amphetamine may result in improved behavior and learning after 15 months trial, and side effects are generally mild. Trials in ADHD with less comorbidity would be expected to show even greater beneficial effects.

A collaborative multimodal treatment study of children with ADHD, the MTA, is described by NIMH collaborators. (Jensen PS et al. Arch Gen Psychiatry Sept 1997;54:865-870). It examines long-term effectiveness of medication vs behavioral treatment vs both in 576 children (age, 7-9 years) with ADHD (96 at each of 6 sites) treated for 14 months and reassessed periodically for 24 months. The first patients were enrolled in 1994 and the last will complete the trial in 1998. Pediatric psychopharmacology is receiving a needed boost from this study initiated by the NIMH, and research findings from short-term trials will be tested in more practical, clinically meaningful settings.

\section{SOMATOSENSORY FUNCTION IN ADHD}

Somatosensory evoked potentials (SEP) and tactile function were tested in $49 \mathrm{ADHD}$ children and 49 controls at the Hebrew University, Jerusalem, Israel. Six sensory integration and praxis tests were used to examine suprathreshold tactile perception. These included finger identification, graphesthesia, localization of tactile stimuli, manual form perception, and kinesthesia. ADHD children performed poorly on these suprathreshold somatosensory tests but within normal limits on a smooth vs rough texture discrimination threshold task. The SEP central components were larger in amplitude in ADHD children compared to controls, which supports the theory of cortical neuronal hyperactivity in ADHD. (Parush S, Sohmer H, Steinberg A, Kaitz M. Somatosensory functioning in children with attention deficit hyperactivity disorder. Dev Med Child Neurol July 1997;39:464-468). (Respond: Marsha Kaitz PhD, Department of Psychology, Hebrew University, 91905, Jerusalem, Israel),

COMMENT. Somatosensory functioning is impaired in ADHD, lending credence to the Ayres sensory integration therapies. Testing for cortical sensory function is included in the pediatric neurology evaluation of children with ADHD.

\section{MEGALENCEPHALY AND DEVELOPMENTAL DELAY}

Neurodevelopmental function, language, academic achievement, visuomotor integration, and motor function were evaluated in 20 nonreferred children, aged 6 to 15 years, with idiopathic megalencephaly (>98th percentile) from a suburban practice, and compared to 19 siblings with normal heads and 16 age-matched controls, at the Olson Huff Center for Child Development, Thoms Rehabilitation Hospital, Asheville, North Carolina. Megalencephaly was associated with impaired performance on upper limb motor proficiency, visuomotor integration, response speed, coordination, and increased mirror movements and other neurologic soft signs. Naming fluency was weak, but receptive vocabulary and academic performance were not affected. (Sandler AD, Knudsen MW, Brown TT, Christian RM Jr. Neurodevelopmental dysfunction among nonreferred children with idiopathic 